\title{
Effect of Duck-meat Intake on Adult Disease Risk Factors in Adult Human Males
}

\author{
Chang Jin Lee ${ }^{1}$, Young Tae Lim², Sung Ho Kang ${ }^{3}$, Ho Sung Jung ${ }^{4}$, Oun Hyun Kim \\ Si Heung Sung ${ }^{5}$, and Hyuk Song ${ }^{5 *}$ \\ ${ }^{1}$ Department of Sports and Leisure Studies, Konkuk Univerisity, Chung-ju 380-701, Korea \\ ${ }^{2}$ Department of Golf Teaching, Konkuk Univerisity, Chung-ju 380-701, Korea \\ ${ }^{3}$ Department of Otolaryngology, Konkuk University, Chungju 380-701, Korea \\ ${ }^{4}$ Department of Emergency Medicine, Konkuk University, Chungju 380-701, Korea \\ ${ }^{5}$ Department of Animal and Food Bioscience, Konkuk Univerisity, Chung-ju 380-701, Korea
}

\begin{abstract}
This study was conducted to evaluate the effects of duck-meat consumption on adult disease risk factors, including body compositions, hematological variables, and serum metabolic and lipid profiles in adult human males. To obtain results, 20 adult males aged 20 to 25 were subjected to a diet of $600 \mathrm{~g} /$ day of duck-meat for $4 \mathrm{wk}$, after which body composition, hematological variables, and serum metabolic and lipid profiles were investigated to determine if there was a relationship between duck-meat consumption and adult disease risk factors. The results revealed that high amounts of duck-meat intake did not negatively alter body indices such as body weight, fat mass, body mass index (BMI), \% body fat or waste-to-hip ratio (WHR). Furthermore, there were statistically insignificant changes in the number of blood cells, although this number did increase significantly following intake of duck-meat. Moreover, general decreases in serum metabolic parameters were observed, but none of these changes were significant with the exception of the concentration of blood urea nitrogen (BUN). The serum concentrations of LDL-cholesterol also showed a statistically significant decrease by $5.86 \%$. Therefore, this study suggests that the ingestion of duck-meat not only significantly increased the RBC count but also decreased BUN and LDL-cholesterol concentrations in adult males.
\end{abstract}

Key words: duck-meat, adult disease risk factor, BUN, cholesterol, RBC, LDL-cholesterol

\section{Introduction}

Because of the antidote effects, duck-meat is generally used in traditional medicine in oriental countries. Besides of antidote effects, it has been applied to treat hypertension, stroke, neuralgia, atherosclerosis, obesity, tuberculosis, and gastritis in Korean medicine (Hu, 1994a,b). As a source of nutrition, duck meat contains a variety of essential amino acids and provides good quality proteins (Nam and Lee, 1981). Duck-meat also has a high ratio of phospholipids (particularly lecithin) and unsaturated fatty acids when compared to other meats (Nam, 1997). In addition, duck-meat is known as an alkaline food, therefore consumption of the duck-meat have an anti-aging

*Corresponding author: Hyuk Song, Department of Animal and Food Science, Konkuk University, Chung-Ju 380-701, Korea. Tel: 82-43-840-3522, Fax: 82-43-842-3522, E-mail: lovelyhusband @kku.ac.kr effect by the prevention of acidification of the human body (Kim and Kim, 2003; Nam, 1997).

The serum cholesterol concentration in human adult males and females was significantly reduced by duckmeat consumption for nine days (Nam, 1979). In an animal study, consumption of duck oil decreased triglyceride concentrations, but did not alter total cholesterol or hepatic total lipid concentrations in male Sprague-Dawley rats (Koh et al., 1995). In a type I diabetes model mice, treatment of duck egg oil showed a decrease in blood glucose level and total cholesterol concentrations that occurred in a dose dependent manner (Kim and Ryu, 1998). Moreover, duck egg oil was found to have antiproliferation effects in sarcoma-180 cancer cells (Kim and Ryu, 1998), mouse mammary carcinoma, mouse leukemia, and human hisocytic lymphoma cells (Ryu et al., 2002). Duck egg oil also significantly increased the numbers of $\mathrm{CD} 4^{+}$and $\mathrm{CD} 8^{+} \mathrm{T}$ cells and elevated the level of IL-2 receptor and TNF- $\alpha$ expression (Ryu et al., 2002). 
Anti-proliferative effects of the cancer cell line in response to treatment with sulfur fed duck extracts have also been studied in various cancer cell lines, that treatment with extracts from sulfur fed ducks effectively inhibited the proliferation of human and mouse cancer cell lines (Choi and Kim, 2002). Moreover, purified antitumor substances from sulfur fed ducks effectively reduced the growth rate of Hep-2 (human larynx) and KB (human epidermoid of mouth carcinoma) cells (Yoon et al., 2004).

The mitigation effect of duck extracts on heavy-metal exposure has been reported as a putative function of duck products. Feeding duck products to rats that were exposed to mercury $(\mathrm{Hg})$, cadmium $(\mathrm{Cd})$, and lead $(\mathrm{Pb})$ resulted in decrease of these heavy-metals accumulation in tissues, and an increase of their excretion (Han et al., 2003). Indeed, the activities of GOT (glutamic oxalacetic transaminase), GPT (glutamic pyruvate transaminase) and BUN (blood urea nitrogen) of serum were significantly reduced in rats fed duck products, and suppressing effects of the accumulation of $\mathrm{Hg}$ and $\mathrm{Pb}$ in the serum of these animals were also observed (Park et al., 2005).

Although the beneficial effects of duck products in human and animal models are well known and their functional importance to the regulation of adult disease factors have been demonstrated in several studies, other functions of duck products are poorly understood in humans. In the present study, we provided duck-meat to human males for four weeks and then analyzed various adult disease factors to investigate the relationship between duckmeat consumption and adult disease factors.

\section{Materials and Methods}

\section{Experimental subjects}

Twenty students aged 20 to 25 from Konkuk university, Chungju, Korea, were subjected to a duck-meat diet consumption experiment. The participants were resided in dormitory that equipped an internal kitchen with a dietician. They were also carefully instructed not to change their diets or their lifestyle during the experimental period. Information on the healthy status of subjects was obtained by an interview on the lifestyle and medical history, and a physical examination. All study participants were in good health. They denied having dyspepsia or other gastrointestinal diseases, and did not take any medication. They also did not have the hypertension, diabetes mellitus and other chronic illness. The participants were informed of the objective and process of the experiment and gave their written consent.

\section{Control of subjects}

The subjects were controlled to avoid an irregular life pattern and excessive exercise to eliminate unexpected variations in the experimental results. Part of these controls included prohibition of alcohol and caffeine consumption during the experiment. In addition, the subjects were urged regulations that included living in a dormitory, prohibition of dining out and avoiding the excessive consumption of sweet things during the study.

\section{Control of diet}

All subjects in the experimental group were given three meals a day containing $600 \mathrm{~g}$ of duck-meat in various dish styles designed by a dietician for four weeks. The energy level of duck-meat is $134 \mathrm{kcal} / 100 \mathrm{~g}$, therefore consumption of $600 \mathrm{~g} /$ day is equivalent to $804 \mathrm{kcal} /$ day. The styles of duck-meat dishes were diverse, that included a smoked (boneless), fried, steamed and roast (boneless), etc. Dietician decided the dish style by the daily request of the subjects, and the subjects consumed the prepared duck-meat dishes. Total $12 \mathrm{~kg} /$ day of duck-meat was prepared for the subjects, and the subjects consumed all prepared dishes. However, the individual subject did not take exactly $600 \mathrm{~g}$, but the subjects group consumed all prepared duck-meat dishes. In addition, the remains of meal were allowed, but the remains of duck-meat were not allowed.

\section{Body composition analysis}

The changes in body composition were also investigated. Body weight, body fat, percentage body fat ( $\%$ fat), body mass index (BMI) and waste heap ratio (WHR) were measured before and after the duck-meat diet consumption using an InBody 4.0 body analyzing machine (Biospace, Seoul, Korea)

\section{Adult disease factor analysis}

Blood samples $(10 \mathrm{~mL})$ were collected one day prior to the experiment and one day after the experiment ended and then analyzed for adult disease risk factors. The blood samples were collected between 7:00 and 9:00 AM after a $10 \mathrm{~h}$ fast of last meal. Blood samples were collected in Heparin or EDTA containing tubes (Becton Dickinson, USA) and then incubated for one hour at room temperature. The samples were then centrifuged at 3,500 rpm for $15 \mathrm{~min}$, after which they were subjected to further analysis. Specifically, the samples were analyzed for the following adult disease factors at Konkuk University Chungju Hospital: Hematological variables - WBC (white blood 
cells), RBC (red blood cells), HGB (hemoglobin), PLT (platelets), TP (total protein), ALB (albumin); Liver function test - AST aspartate aminotransferase), ALT (alanine aminotransferase), ALP (alkaline phosphatase), and GGT (gamma glutamyl transferase); Renal function test - BUN (blood urea nitrogen) and CRE (creatinine); Serum lipid profiles - TC (total cholesterol), TG (triglyceride), HDL (high density lipoprotein))-cholesterol, and LDL (low density lipoprotein)-cholesterol.

\section{Statistical analysis}

The SPSS statistical package ver. 15.0 for Windows was utilized and all data shown are the means \pm the standard deviation. The values before and after the subject ate duck meat were compared by a paired t-test. The null hypothesis was rejected when the probability was less than 0.05 .

\section{Results and Discussion}

\section{Body compositions}

The body weight, fat mass, BMI, \% body fat and WHR were compared before and after daily consumption of 600 $\mathrm{g}$ of duck-meat. As shown in Table 1, the body weight, fat mass, BMI, \% body fat and WHR increased by 0.16 $\mathrm{kg}, 0.03 \mathrm{~kg}, 0.05 \mathrm{~kg} / \mathrm{m}^{2}, 0.04 \%$, and $0.001 \%$, respectively, following the consumption of duck meat; however, these changes were not significant. It is well known that obesity increases the risks of a number of chronic diseases, such as cardiovascular disorders, hypertention, diabetes, and certain types of cancer (Word health Organization, 2000). Moreover, meat consumption is associated with a higher intake of total fat, saturated fat and total calories, and an increased risk of chronic diseases such as cardiovascular disease (Nicklas et al., 1995). Recently, Wang and Beydoun reported that the risk for obesity and central obesity is positively associated with BMI and waist circumference (Wang and Beydoun, 2009). However, our data indicated that consumption of duck meat did not

Table 1. Changes in body composition pre- and post-consumption of duck meat ${ }^{1)}$

\begin{tabular}{clrr}
\hline \hline Variable & \multicolumn{1}{c}{ Item } & \multicolumn{1}{c}{ Pre } & \multicolumn{1}{c}{ Post } \\
\hline & Weight $(\mathrm{kg})$ & $82.54 \pm 7.39$ & $82.70 \pm 7.31$ \\
Body & Fat mass $(\mathrm{kg})$ & $13.23 \pm 3.29$ & $13.26 \pm 2.84$ \\
composition & BMI $\left(\mathrm{kg} / \mathrm{m}^{2}\right)$ & $25.43 \pm 1.64$ & $25.48 \pm 1.59$ \\
& \% Body fat (\%) & $15.96 \pm 3.26$ & $16.00 \pm 2.78$ \\
& WHR (\%) & $0.86 \pm 0.02$ & $0.86 \pm 0.02$ \\
\hline
\end{tabular}

${ }^{1)}$ Values are presented as the mean $\pm \mathrm{SD}$.

BMI, body mass index; WHR, waste heap ratio. alter the parameters of body compositions or obesity indices such as BMI and WHR, even after a high intake of duck meat ( $600 \mathrm{~g} /$ day for $4 \mathrm{wk}$ ), which suggests that duck meat consumption does not pose a risk of obesity

\section{Hematological variables}

The concentrations of WBC (white blood cells), RBC (red blood cells), HGB (hemoglobin), PLT (platelets), TP (blood total protein) and ALB (albumin) were compared before and after daily consumption of $600 \mathrm{~g}$ of duck-meat (Table 2). The WBC, HGB and TP levels increased by $0.03 \times 10^{3}$ cells/uL, $0.06 \mathrm{~g} / \mathrm{dL}$ and $0.04 \mathrm{~g} / \mathrm{dL}$, respectively, but these changes were not statistically significant. However, RBC increased significantly by $0.09 \times 10^{6}$ cells $/ \mathrm{uL}$. PLT and ALB were decreased by $2.55 \times 10^{3}$ cells $/ \mathrm{uL}$ and $0.02 \mathrm{~g} / \mathrm{dL}$, respectively, but this difference was not significant. Generally, RBC are generated by erythrocytes produced in the kidney and are involved in the transportation of oxygen bound hemoglobin to tissues and cells in the bodies of animals (McMullin, 2009). In another study, increased $\mathrm{RBC}$ in rats following of the consumption of duck products was also detected that heavy metal exposed rats fed duck by-products supplemented with medicinal herbs showed a significant increase in RBC to levels that were even higher than in normal rats (Park et al., 2005). Therefore, the increase in $\mathrm{RBC}$ in response to the consumption of duck meat intake indicates that duck meat may positively influence oxygen metabolism by providing a sufficient supply of oxygen to the body. Accordingly, the intake of duck meat may help prevent or alleviate $\mathrm{RBC}$ deficiency related diseases such as anemia.

\section{Liver and renal function test (Serum metabolic)}

The concentrations of AST, ALT, ALP, and GGT were compared before and after daily consumption of $600 \mathrm{~g}$ of duck-meat (Table 3). Although no significant differences

Table 2. Changes in hematological variables of pre- and postconsumption of duck meat ${ }^{1)}$

\begin{tabular}{clrc}
\hline \hline Variable & \multicolumn{1}{c}{ Item } & \multicolumn{1}{c}{ Pre } & \multicolumn{1}{c}{ Post } \\
\hline & WBC $\left(10^{3}\right.$ cells/uL $)$ & $6.33 \pm 1.10$ & $6.36 \pm 1.10$ \\
& RBC $\left(10^{6}\right.$ cells $\left./ \mathrm{uL}\right)$ & $5.21 \pm 0.21$ & $5.30 \pm 0.21^{*}$ \\
Hematological & HGB $(\mathrm{g} / \mathrm{dL})$ & $15.96 \pm 0.60$ & $16.02 \pm 3.27$ \\
variables & PLT $\left(10^{3}\right.$ cells $\left./ \mathrm{uL}\right)$ & $258.70 \pm 40.51$ & $256.15 \pm 42.76$ \\
& TP $(\mathrm{g} / \mathrm{dL})$ & $7.24 \pm 0.25$ & $7.28 \pm 0.38$ \\
& ALB $(\mathrm{g} / \mathrm{dL})$ & $4.50 \pm 0.14$ & $4.48 \pm 0.16$
\end{tabular}

${ }^{1)}$ Values shown represent the mean $\pm \mathrm{SD}$, and asterisks indicate statistical significance, ${ }^{*} p<0.05$

WBC, white blood cell; RBC, red blood cell; Hb, hemoglobin; PLT, platelet; TP, total protein; ALB, albumin. 
Table 3. Changes in serum metabolic enzymes (liver function) pre- and post-consumption of duck meat

\begin{tabular}{ccrr}
\hline \hline Variable & Item & \multicolumn{1}{c}{ Pre } & \multicolumn{1}{c}{ Post } \\
\hline & AST (iu/L) & $24.25 \pm 12.78$ & $23.95 \pm 6.54$ \\
Liver activity & ALT (iu/L) & $19.45 \pm 7.15$ & $18.60 \pm 5.63$ \\
& ALP (iu/L) & $293.65 \pm 81.09$ & $291.55 \pm 85.32$ \\
& GGT (iu/L) & $18.45 \pm 6.05$ & $17.10 \pm 6.27$
\end{tabular}

Values shown are the mean $\pm \mathrm{SD}$.

AST: aspartate aminotransferase, ALT: alanine aminotransferase, ALP: alkaline phosphatase, GGT: gamma glutamyl transferase.

were observed in any of the examined liver enzymes, AST, ALT, ALP, and GGT decreased by 0.3, 0.85, 2.10, and $1.35 \mathrm{iu} / \mathrm{L}$, respectively. ALT is liver specific and increases in response to chronic and acute hepatitis, fatty liver, alcoholic hepatitis, and liver cancer, whereas AST increases in response to heart, liver, skeleton, renal, and pancreatic disorders (Kim et al., 2001; Lee et al., 1999). In other studies, it has been reported that feeding duckextracts to mice exposed to heavy metals induced a significant decrease in AST and ALT, but that ALP and LDH (lactate dehydrogenase) were not changed (Han et al., 2003; Park et al., 2005).

For the renal function test, the blood concentration of BUN and creatinine were analyzed. The concentrations of both enzymes were reduced, with that of BUN being significantly reduced by $1.38 \mathrm{mg} / \mathrm{dL}$ (Table 4). However, the concentration of creatinine was reduced by $0.02 \mathrm{mg} / \mathrm{dL}$, but did not show any significant. According to a Korean traditional medicinal book, 'Dong Ui Bo Gam', duck meat has an outstanding effect on deintoxication $(\mathrm{Hu}$, 1994a,b). Generally, BUN increases in response to renal disorders, and it is used as an indicator of renal activity (Kim et al., 2001). It has been reported that intake of duck by-products supplemented with medicinal herbs effectively diminished the concentration of BUN and that of heavy-metals in rats exposed to mercury chloride $\left(\mathrm{HgCl}_{2}\right)$ and lead acetate $\left[\mathrm{Pb}\left(\mathrm{CH}_{3} \mathrm{COO}\right)_{2}\right]$ (Han et al., 2003; Park et al., 2005). In this study, BUN was also significantly reduced in response to the intake of duck meat.

Table 4. Changes in serum metabolic enzymes (renal function) pre- and post-consumption of duck meat

\begin{tabular}{cccc}
\hline \hline Variable & Item & Pre & Post \\
\hline Kidney & $\mathrm{BUN}(\mathrm{mg} / \mathrm{dL})$ & $19.70 \pm 1.81$ & $18.32 \pm 2.12^{*}$ \\
function test & $\mathrm{CRE}(\mathrm{mg} / \mathrm{dL})$ & $1.13 \pm 0.07$ & $1.11 \pm 0.08$ \\
\hline
\end{tabular}

Values shown are the mean $\pm \mathrm{SD}$, and asterisks indicate statistical significance, ${ }^{*} p<0.05$

BUN: blood urea nitrogen, CRE: creatinine.
Taken together, the results of these previous studies and the present investigation provide evidence for the role of duck-meat intake on deintoxication that is reported in Korean traditional medicinal books. Overall, these results indicate that the intake of duck-meat by adult humans has a positive influence on renal function that occurs via a decrease in BUN, which suggests that intake of duckmeat may enhance renal ability or prevent renal disorder through a decrease in BUN.

\section{Serum lipid profile}

Changes in the serum lipid levels were identified following the ingestion of duck meat (Table 5). Specifically, the HDL-cholesterol increased by $1.60 \mathrm{mg} / \mathrm{dL}$, however the TC, TG, and LDL-cholesterol levels decreased by $3.75,2.90$, and $5.45 \mathrm{mg} / \mathrm{dL}$, respectively. Among the analyzed serum lipids, the LDL-cholesterol was significantly decreased by $5.86 \%$. In Korea, body activity has recently been reduced in response to a more convenient life style, and cardiovascular disorders have been rapidly increasing as a result of arteriosclerosis following the introduction of westernized foods (Khor, 1997; Hu et al, 1997; Moon and Jung, 1994). Indeed, death by cardiovascular disorder now accounts for $23.8 \%$ of all deaths in Korea (National statistical office, 2006). Furthermore, hypertension, low levels of HDL-cholesterol and high levels of LDL-cholesterol, family history, and older age are regarded as risk factors for cardiovascular disorder (The 3rd report of the NCEP, 2001), but an imbalance of serum lipid levels has been reported as the most important risk factor (Castelli, 1984; Castelli et al., 1986; Connor et al, 1994; Preuss, 1993). Hypercholesterol caused by food intake has been shown to cause an increase in TG through an increase of serum cholesterol and VLDL-cholesterol via the upregulation of LDL-cholesterol as a consequence of eating foods with high amounts of fat, saturated fatty acid and cholesterol, and this has often been associated with increased LDL-cholesterol and decreased HDL-choles-

Table 5. Changes in serum lipids profile pre- and post-consumption of duck meat

\begin{tabular}{clcc}
\hline \hline Variable & \multicolumn{1}{c}{ Item } & Pre & Post \\
\hline \multirow{3}{*}{ Serum } & TC $(\mathrm{mg} / \mathrm{dL})$ & $162.80 \pm 20.04$ & $159.05 \pm 23.67$ \\
lipid & HDL $/ \mathrm{dL})$ & $66.00 \pm 15.49$ & $63.10 \pm 22.73$ \\
& HD-cholesterol (mg/dL) & $60.60 \pm 14.87$ & $62.20 \pm 8.64$ \\
& LDL-cholesterol (mg/dL) & $92.95 \pm 17.87$ & $87.50 \pm 18.84^{*}$
\end{tabular}

Values shown are the mean $\pm \mathrm{SD}$, and asterisks indicate statistical significance, ${ }^{*} p<0.05$

TC: total cholesterol, TG: triglyceride, HDL: high density lipoprotein, LDL: low density lipoprotein. 
terol (Guide for clinical nutrition, 2002).

In this study, we found decreased $\mathrm{TC}$ and $\mathrm{TG}$, and increased HDL-cholesterol following the intake of duckmeat, although these differences were not significant. Additionally, a significant difference in LDL-cholesterol concentration was observed in healthy adult humans following the ingestion of duck-meat, indicating that it may have a positive effect for preventing cardiovascular disorders mediated by hypercholesterol.

Duck-meat has been identified as an excellent source of niacin (vitamin B3), and 100 gram of duck-meat provides about $50 \%$ of the daily requirements for niacin. Interestingly, this vitamin played an important role in the metabolism of fats by cholesterol-lowering effects (Costet, 2010). Clinical demonstration study revealed that patient with high level of TG and LDL-cholesterol ingested 500$1500 \mathrm{mg} /$ day of niacin for $16 \mathrm{wk}$, showed a significant decrease in total cholesterol, TG and LDL-cholesterol (Wi et al, 2010). Although the precise mechanism of duck-meat intake in lowering LDL-cholesterol level was not determined, the therapeutic effect of niacin in certain patients may provide the indirect evidence of duck-meat in lowering blood lipids. Support of this, decreased human blood cholesterol levels in response to the intake of duck-meat were also reported after nine days of intake of canned duck-meat, which was associated with decreases in the blood cholesterol of $187 \mathrm{mg} \%$ to $178.8 \mathrm{mg} \%$ in human males and $184 \mathrm{mg} \%$ to $173.8 \mathrm{mg} \%$ in human females (Nam, 1979). Furthermore, an animal study revealed that feeding duck oil to male Sprague-Dawley rats induced a decrease in triglyceride and total cholesterol (Koh et al, 1995). Taken together, our results indicated that duck-meat consumption may prevent or treat cardiovascular disorders via a decrease in blood lipids.

In summary, this study investigated the effects of duckmeat consumption by human males on body composition, hematological variables, liver and renal function, and changes in serum lipids changes. High amounts (600 g/ day/man) of duck-meat intake did not increase the body indices such as body weight, fat mass, BMI, \% body fat and WHR, but the RBC count was significantly increased by $1.7 \%$ following the intake of duck-meat. Moreover, the intake of duck-meat generally decreased the serum metabolic parameters, but this difference was not significant, except for the BUN concentration which was significantly decreased by $7 \%$. Regarding the serum lipids concentrations, high risk factors for cardiovascular disorders such as TC, TG and LDL-cholesterol were generally decreased, but LDL-cholesterol was significantly decre- ased by $5.38 \%$. Therefore, duck-meat may be a healthy food that is able to enhance the body metabolism by the increase of RBC number, and the decrease of BUN and LDL-cholesterol concentrations.

\section{Acknowledgements}

This work was supported by Konkuk University in 2010 .

\section{References}

1. Castelli, W. P. (1984) Epidemiology of coronary heart disease. The Framingham Study. Am. J. Med. 76(Supple)2A, 412.

2. Castelli, W. P., Garrison, R. J., Wilson, P. W., Abbott, R. D., Kalousdian, S., and Kannel, W. B. (1986) Incidence of coronary heart disease and lipoprotein cholesterol levels. The Framingham Study. JAMA. 256, 2835-2838.

3. Choi, G. H. and Kim, C. H. (2002) Growth inhibition of extract from sulfur fed duck carcass against various cancer cell lines. Korean J. Food Sci. Anim. Resour. 22, 348-351.

4. Connor, W. E., Stone, D. B., and Hodges, R. E. (1994) The interrelated effects of dietary cholesterol and fat upon human serum lipid levels. J. Clin. Invest. pp. 1692-1696.

5. Costet, P. (2010) Molecular pathways and agents for lowering LDL-cholesterol in addition to statins. Pharmacol. Ther. 126, 263-278.

6. Guide for Clinical Nutrition. (2002) Korean Dietician Association Corporation. pp. 159-172.

7. Han, J. H., Lee, W. J., Jo, S. G., Lee, M. J., Jeong, M. R., Chon, J. W., Kim U. Y., and Park, S. H. (2003) Nutritional characteristics and damage mitigation effects on heavy-metals exposure of peking-duck by-product extracts added with medicinal herbs (II) damage mitigation effects on heavymetals exposure of peking-duck by-product extracts. $J$. East Asian Soc. Dietary Life. 13, 293-304.

8. Hu, F. B., Stampfer, M. J., Manson, J. E., Rimm, E., Colditz, G. A., Rosner, B. A., Hennekens, C. H., and Willett, W. C. (1997) Dietary fat intake and the risk of coronary heart disease in women. N. Engl. J. Med. 337, 1401-1499.

9. Hu, J. (1994a) Dong Eui Bo Gam I - Nai Kyung part. Yugan press Co. Ltd.

10. Hu, J. (1994b) Dong Eui Bo Gam - Tang Aik part Duck jo, Yugan press Co. Ltd.

11. Khor, G. L. (1997) Nutrition and cardiovascular disease: An Asia-Pacific perspective. Asia Pac. J. Clin. Nutr. 6, 122-142.

12. Kim, J. S. and Kim, W. K. (2003) Effects of duck extract on lipids in rats. Korean J. Nutr. 10, 3-8.

13. Kim, N. J. and Ryu, B. H. (1998) Functional characteristics of egg oil extracted from duck's. Korean J. Food \& Nutr. 11, 41-46.

14. Kim, S. J., Bak, S. W., Lee, J. D., Kim, U. S., Moon, K. H., Yim, H. B., Heo, J. W., and Jeong, S. Y. (2001) Effect of fed 
chlorella on the change of lipid components and enzyme acivity in serum of rat by lead exposure. Korean J. Food \& Nutr. 14, 138-144

15. Koh, J. B., Jung, B. M., Kim, J. Y., and Rho, M. H. (1995) Effects of duck oil on serum and organ lipid composition in mature rats. J. Korean Soc. Food \& Nutr. 24, 874-879.

16. McMullin, M. F. (2009) Idiopathic erythrocytosis: a disappearing entity. Hematology Am. Soc. Hematol. Educ. Program Book, Vol. 2009, pp. 629-635.

17. Moon, H. K. and Joung, H. J. (1994) Dietary risk factors of hypertension in the elderly. Korean J. Nutr. 32, 767-773.

18. Nam, H. K. (1979) Studies on the effect of Duck-meat on human blood cholesterol level. J. Korean Soc. Food \& Nutr. 8, 37-42.

19. Nam, H. K. and Lee, Y. O. (1981) A study of the Bio-Nutritional evaluation of duck-meat. Korean J. Nutr. 14, 16-25.

20. National Statistical Office. (2005) Annual report of the cause for death statistics in 2004.

21. Nicklas, T. A., Farris, R. P., Myers, L., and Berenson, G. S. (1995) Impact of meat consumption on nutritional quality and cardiovascular risk factors in young adults: the Bogalusa Heart Study. J. Am. Diet Assoc. 95, 887-892.

22. Park, S. H., Shin, E. H., Park, S. J., and Han, J. H. (2005) Effect of peking-duck by-product extracts supplemented with medicinal herbs on serum heavy metal levels and blood parameters of rats exposed to lead and mercury. J. Korean Soc. Food \& Nutr. 34, 476-483.
23. Preuss, H. G. (1993) Nutrition and diseases of women: Cardiovascular disorders. J. Am. Coll. Nutr. 12, 417-425.

24. Ryu, B. H., Kim, M. J., and Yang, S. T. (2002) Antitumor effects of duck's egg oil on the cancer cells. Korean J. Life Sci. 12, 61-66.

25. Third report of the National Cholesterol Education Program (NCEP)-Detection, evaluation, and treatment of high blood cholesterol in adults (Adult treatment panel III). (2001) US Department of Health and Human Services, NIH Publication No. 01-3670.

26. Wang, Y. and Beydoun, M. A. (2009) Meat consumption is associated with obesity and central obesity among US adults. Int. J. Obes. 33, 621-628.

27. Wi, J., Kim, J. Y., Park, S., Kang, S. M., Jang, Y., Chung, N., Shim, W. H., Cho, S. Y., and Lee, S. H. (2010) Optimal pharmacologic approach to patients with hypertriglyceridemia and low high-density lipoprotein-cholesterol: Randomized comparison of fenofibrate $160 \mathrm{mg}$ and niacin $1500 \mathrm{mg}$. Atherosclerosis. 213, 235-240

28. World health Organization. (2000) Obesity: preventing and managing the global epidemic. Technical report series. World Health Orgnanization: Geneva, Switzerland. 894, 1-253.

29. Yoon, W. H., Hwang, J. W., and Kim, C. H. (2004) Isolation and purification of antitumor substance from the sulfur fed duck. Korean J. Food Sci. Anim. Resour. 24, 293-297.

(Received 2010.8.6/Revised 1st 2010.12.4, 2nd 2010.12.7/ Accepted 2010.12.8) 